Shifting towards environment-friendly modes: profiling travelers using q-methodology Peer-reviewed author version

COOLS, Mario; MOONS, Elke; Janssens, B. \& WETS, Geert (2009) Shifting towards environment-friendly modes: profiling travelers using q-methodology. In: TRB 88th Annual Meeting Compendium of Papers DVD..

Handle: http://hdl.handle.net/1942/10599 


\title{
SHIFTING TOWARDS ENVIRONMENT-FRIENDLY MODES: PROFILING TRAVELERS USING Q-METHODOLOGY
}

\author{
Mario Cools, Elke Moons, Brecht Janssens, Geert Wets ${ }^{*}$ \\ Transportation Research Institute \\ Hasselt University \\ Wetenschapspark 5, bus 6 \\ BE-3590 Diepenbeek \\ Belgium \\ Fax.: +32(0)11269199
}

\author{
Mario Cools \\ Tel.: +32(0)11269131 \\ Email: mario.cools@uhasselt.be \\ Elke Moons \\ Tel.: +32(0)11269126 \\ Email: elke.moons@uhasselt.be \\ Brecht Janssens \\ Tel.: +32(0)486127643 \\ Email.: brecht.janssens@student.uhasselt.be \\ Geert Wets \\ Tel.: +32(0)11269158 \\ Email: geert.wets@uhasselt.be \\ * Corresponding author
Number of words $=6214$
Number of Figures $=2$ \\ Number of Tables $=3$ \\ Words counted:6214 $+5 * 250=7464$ words
}

Paper submitted: November 13, 2008 


\begin{abstract}
Due to a variety of reasons, the previous century is characterized by an extraordinary growth in car use that has continued into the current century. This has resulted in serious environmental repercussions. Despite technological advancements, the externalities remain an ecological threat that can not be discarded by policy makers. Therefore, it is essential that policy makers focus on reducing car use and on stimulating the shift towards more environment-friendly transport modes. In this study, Q-methodology is adopted as the technique to segment people, and to ascertain which approaches and determinants matter to medium distance travel. Segmentation is important, as policy measures will be more efficient and effective if they are fine-tuned on specific target groups. The analysis revealed that four discourses preponderate the paradigm of environmentally sustainable transport: travelers who use public transport as a dominant alternative, car-dependent travelers, travelers with a positive perception of using public transport, and travelers with a preference for car use. Concerning rational, economic motives, individuals evaluate travel time reliability as most important. To increase the reliability policy makers should consider the use of separate bus lanes and traffic light manipulation. In addition, public transport can be made even more attractive, when costs of cars are made more variable by road or congestion charging. When the subjective motives are discussed, the differences between the different groups of travelers were more pronounced. Next to increasing the benefits of using public transport, policy makers should also pay attention to removing psycho-social barriers.
\end{abstract}




\section{BACKGROUND}

Due to a variety of reasons ranging from the intrinsic appeal of automobiles, urban sprawl, increasing demands of the labor market with regard to employees' flexibility and mobility, increasing female participation in labor, to a decline in traditional household structures, the previous century is characterized by an extraordinary growth in car use that has continued into the current century (1). As a result, in today's society, cars play a dominant role in the travel behavior of people, causing serious environmental (e.g. greenhouse-emissions such as $\mathrm{CO}_{2}$, methane, $\mathrm{NO}_{x}$; noise, odor annoyance and acid precipitation), economic (e.g. use of nonrenewable energy sources; and the time lost due to congestion) and societal (e.g. health problems such as cardiovascular and respiratory diseases; traffic casualties; community severance and loss of community space) repercussions (2).

Despite technological advancements that make cars more environment-friendly, the externalities caused by car use remain an ecological threat that can not be discarded by policy makers (3). Therefore, it is essential that policy makers focus on reducing car use and on stimulating the shift towards more environment-friendly transport modes (4). It is clear that people are aware of the negative side-effects of their car-use, and that there is a willingness to use alternatives (5). Notwithstanding, non-coercive travel demand management (TDM) measures alone are unlikely to be effective in reducing car use. Therefore coercive TDM measures such as increasing costs for or prohibiting car use may be necessary (3). Before implementing TDM measures, it is essential to understand the processes underlying people's motivation to change their travel behavior. One approach to gain such knowledge is to apply well established social psychological models, such as for instance Ajzen's theory of planned behavior, or Schwartz' norm activation model to the explanation of people's travel and modal choices (6).

For medium-distance trips $(10-100 \mathrm{~km})$, public transport (PT) is considered to be a valuable alternative for car use. To promote public transport, comprehensive approaches including policy, design, economic, social and psychological components are needed. Mobility plans formulated by government agencies at different policy levels, as for instance the "Mobility plan Flanders" (7) at Belgian regional level, stipulate potential roadways to increase the share of public transport users, focusing on an increase in both the quantity (supply) and quality (attractiveness) of public transport options.

The last years, the modal split is certainly shifting in the desired direction. The number of train tickets sold (Figure 1 upper left corner) and the number of bus tickets sold (Figure 1 upper right corner) increased significantly with about 40\% and 120\% from 1990 until 2006. However, these sharp increases do not prove an actual shift towards public transport, since the fleet of cars augmented as well. To substantiate whether a shift really took place, the relative share of passenger kilometers made by public transport in the total number of passenger kilometers has to be investigated. When the relative share of passenger kilometers made by train (Figure 1 lower left corner) and made by bus (Figure 1 lower right corner) are examined, it can be seen that the share of public transport is increasing, the share of train use increasing more rapidly than the share of bus use. 

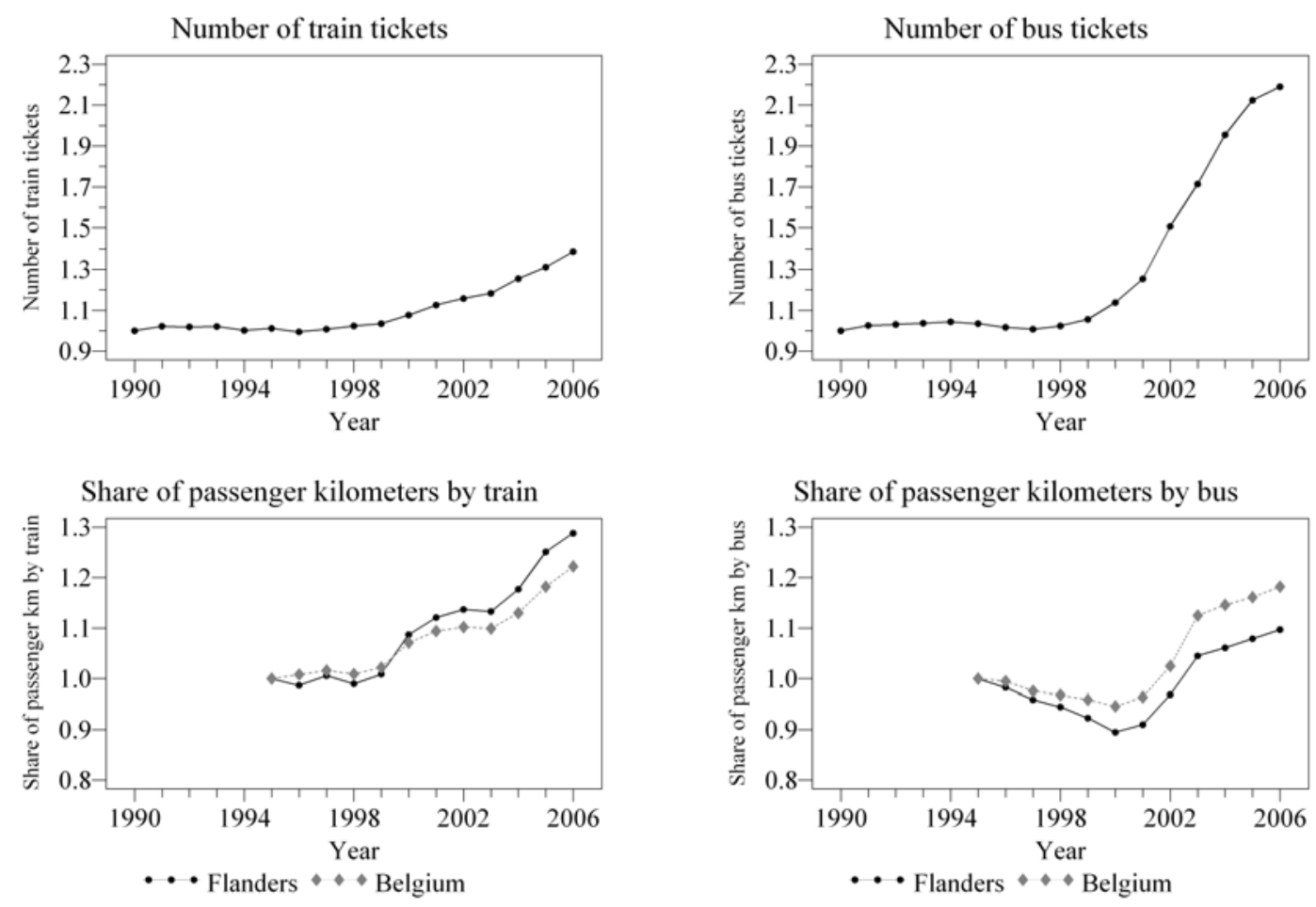

FIGURE 1 Evolution of public transport (8).

\subsection{Determinants for Modal Choice}

To develop efficient policy measures to further stimulate the use of public transport, a clear insight in the determinants of the modal choice between car use and public transport is required. The choice of transport mode is a complex process that is influenced by several factors, such as socio-demographic variables, psycho-sociological variables, the type of journey, the perceived service performance of each transport mode and situational variables (9). Both attitudes towards flexibility and comfort, as well as being pro-environmentally inclined, influence the individual's choice of mode (10). Car use is not only preferred to public transit for its instrumental function (it enables activities), but also for its symbolic (car is a means to express yourself or your social position) and affective (driving is pleasurable and arousing) function (11).

Socio-demographic variables that aid in explaining structural differences in modal choice include age, gender, household income, professional occupation, education level, family structure and car ownership (9). Women, younger people, low-income groups and singles tend to use their car relatively less often than men, older age groups, higher income groups, couples and families (2).

The impact of psycho-sociological variables (attitudes, self-efficacy, responsibility, moral or social norms) on behavior is only an indirect one, mediated by behavioral intention. According to the theory of planned behavior, intentions are the closest antecedents of behavior, and in turn intentions result from attitudes (positive or negative evaluations of a specific behavior), subjective norms (perceived social pressure to engage or not to engage in a behavior) and perceived behavioral control (people's perceptions of their ability to perform a 
behavior). The theory of planned behavior further assumes that these components are in turn determined by salient beliefs for each component and evaluations of those beliefs (12).

Among the various attitudinal factors, environmental concern (problem awareness) and car affection seem to be the most important ones (13). Values and problem awareness significantly affect personal norms, which in turn influences the willingness to cooperate in environment-friendly behavior (14). Personal norms are based on two related but distinct processes: anticipated feelings of guilt and perceived social norms (15). The fact that a large majority of people prefer to use the car over public transport could be interpreted as an expression of a triad of very western values: speed, individualism (car journeys are undertaken alone or with 'chosen' passengers) and privatization (car journeys are undertaken in a private space, totally under the driver's control) (16).

Travel related attributes such as travel costs (including model prices and petrol prices), accessibility of destinations, travel distances and especially travel time, and travel time reliability (variability) are key determinations of transport mode decisions (16). For journeys related to work/school activities, time importance is much higher, as nondiscretionary trips have fewer adaptation alternatives than discretionary trips, and moreover, people tend to attach more importance to instrument aspects (especially convenience) for discretionary trips than for non-discretionary trips, where people attach almost equal importance to instrumental and affective aspects (particularly flexibility, relaxation, a sense of freedom and 'no stress') (17).

Finally, the environmental imperative to decrease car usage requires an understanding of the perceived psychosocial benefits and disadvantages of different forms of transport (18). Psycho-social benefits of protection, autonomy and prestige may help to explain people's attachment to cars (19). The "delay of reinforcement” concept proposes that immediate benefits or disadvantages resulting from one's behavior are more potent and are more likely to affect behavior than delayed benefits or disadvantages (20). Benefits of using a car (e.g. convenience and privacy) are very immediate to the user, whereas the disadvantages (e.g. maintenance costs and pollution) are delayed in time, resulting in an environment favoring car use above public transport, for which the benefits are delayed in time (e.g. reduction in pollution and congestion) and the disadvantages are more immediate (e.g. longer travel times and exposure to poor weather). Moreover, while the arguments on the advantages of car use are presented as unquestionable and absolute personal experiences, scientific facts about the negative effects of car use are presented as relative and negotiable, with references to public discourse.

\subsection{Policy Measures}

Various policy measures are proposed for reducing car use and encouraging public transport. Two distinctions can be made between different policy measures. First, a distinction can be made between 'push' and 'pull' measures. Push measures are aimed at directly reducing the attractiveness of car use, while pull measures are aimed at increasing the attractiveness of alternative transport modes. Second, one could discriminate between 'hard' and 'soft' measures. Practical strategies considered as 'hard' are the provision of infrastructure and other physical and/or technical facilities, hard regulation and significant pricing policies. Practical strategies considered as 'soft' are information provision, education and persuasive 
advertising. The latter are meant to change people's knowledge, perceptions, evaluations, intentions and expectations, and their longer-term norms and values (21).

If car use is to be reduced and travel by public increased, then public transport has to be made a more attractive, convenient transport option (18). The use of worst-case scenarios in general discussions about bus travel highlights how the worst performances may be most influential. This suggest that public transport companies should address the worst aspects of their service as a priority (22). Policy measures should aim at reducing the functional, psychological and cultural values of private car, as well as at increasing the performances of public transport on these aspects (2). Therefore it is important that reliability and travel times of public transport are increased, and that public transport is promoted as a more positive experience, for instance by offering simple and immediate amenities (e.g. newspaper, business magazines, and vending machines) for professionals (20). To ensure acceptability, as well as effectiveness, the policy measures need to be designed carefully and adjusted to the context as well as to the group of car users targeted (23).

Four types of TDM measures can be distinguished which are targeting different antecedents of travel demand, namely physical changes, legal policies, economic policies, and information and educational measures (3). The first category, physical changes, aims at increasing the relative attractiveness of alternative travel modes. Possible measures include the improvement of public transport (more bus stops, higher frequency, more comfort), the laying of separate (priority) bus lanes, land use planning to encourage shorter travel times and technological advancements to make cars more energy-efficient (3). The second category of policy measures, legal policies, tries to enforce a reduction in car use. Prohibiting car traffic in city centers, parking control, and decreasing speed limits, are some examples of this type of policy measures (24). Economic policies, the third category of TDM measures, make car use relatively more expensive. Examples are taxation of cars and fuel, road or congestion charging (congestion charges are already introduced in cities like London, Stockholm and Durham) and decreasing fares for public transport (25). The final category, information and educational measures, focuses on changing people's perceptions, attitudes, beliefs, values and personal norms concerning car use. Possible examples include individualized marketing (e.g. personalized travel planning), public information campaigns about the positive aspects of public transport and the negative aspects of car use, giving feedback about environmental impacts of people's behavior, and social modeling (prominent public figures using public transport) (2).

From the examples described above, it is clear that there is no single route to encourage public transport. The way forward lies in setting clear policy objectives and in assembling TDM measures into strategy packages, ensuring that when combined the measures are complementary towards the policy objectives of travel reduction. Soft measures should be combined with adequate hard measures to attain a more efficient strategy package (24). Moreover, policy measures will be more efficient and effective if they are fine-tuned on specific target groups, as they will better match backgrounds, desires and possibilities of these groups (26). These target groups can be distinguished based on socio-demographic characteristics, behavior, options (e.g. public transport options) and motivations (e.g. car lovers versus car haters). The targeting of people who are confronted with changing decision contexts like changes in place of residence, or changes in occupational status, is an example of how the effectiveness of policy measures can be reinforced by focusing on subgroups of the population, since a new decision context may create a 'sensible phase' in which people's 
attention to new information and their motivation to process it is actively increased (27). Techniques that are used to profile specific target groups include cluster analysis (16), factor analysis (16), discourse analysis (22) and Q-methodology (28). In this study, Q-methodology is adopted as the technique to segment people, and to ascertain which approaches and determinants matter to medium distance travel. The technique is chosen because it does not require a large number of participants in order to generate a diversity of subgroups (28), and because it is extremely suitable for studying environmental behavior; it allows for a responsive but statistically rigorous approach to study the subjective perceptions on humannature relationships, and its results are useful for environmentally sustainable transport policy making (29).

\section{Q-METHODOLOGY}

Q-methodology is a relative little-known form of research methodology within social science, even though it has been established for over 70 years. It was invented by the psychologist William Stephenson in the 1930s, and most applications of Q-methodology have been within psychology, although Q-methodology has been increasingly used in other disciplines, such as political science (29). It is a qualitative but statistical approach that encompasses a distinctive set of psychometric and operational principles, which provides a foundation for the systematic and rigorous study of subjectivity, a person's viewpoint, opinion, attitude, and the like. It offers an innovative way of defining discourses which frame people's views on transport. The discovery of a variety of discourses concerning how individuals understand their travel behavior, and how they understand the environment in which they live, can facilitate the development of effective policy strategies (28). Q-methodology is primarily an exploratory technique, it cannot prove hypotheses. However, it brings a sense of coherence to research questions that have many, potentially complex and social contested answers (30).

In essence, in a Q-methodological study people (P-set) are presented with a set of statements about some topic, called the Q-sample, and then are asked to rank-order the statements (usually from 'agree' to 'disagree'), an operation referred to as 'Q-sorting' (31). By this Q-sorting, people give their subjective meaning to the statements, and so reveal their personal viewpoints. These viewpoints are then subject to factor analysis (32). The strength of Q-methodology is precisely that it allows individual responses to be ordered and correlated. By correlating people, Q-factor analysis gives information about similarities and differences in viewpoints on a particular subject (29). If significant clusters of correlation exist, they could be factorized, and described as common viewpoints (or tastes, preferences, typologies). Thus, Q-methodology is usually practiced in five stages (32): (1) identification of the areas of concourse which one wishes to explore, (2) development of the Q-sample, (3) selection of the P-set, (4) Q-sorting, and (5) analysis and interpretation. For the basic reference on Qmethodology, the reader is referred to Stephenson (33). A good tutorial reference to Qmethodology is written by McKeown and Thomas (32).

\subsection{Concourse}

In Q-methodology, the flow of communicability surrounding a topic is referred to as a 'concourse'. It is a technical concept for the collection of all the possible statements people 
can make about the subject at hand. The concourse is thus supposed to contain all the relevant aspects of all the discourses (31).

In this study, the concourse involves statements about the comparative assessment that people make when choosing between public transport and car use to make medium distance (10-100km) trips.

\subsection{Q-Sample}

A Q-sample is a collection of statements that is presented to the respondents for rank-ordering in a Q-sort. Generally speaking, a Q-sample of somewhere between 40 and 80 statements is considered satisfactory (30). The statements can be elicited from any number of sources: by extensive reference to the academic literature, from both literary and popular texts (magazines, television programs, etc.), from formal interviews and informal discussions, and often via pilot studies (30). The statements neither have to be mutually exclusive, nor completely exhaustive of all possible concepts that could apply.

For this study, the Q-sample contains 42 statements (Table 1) adopted from van Exel et al. (34). The Q-sample is a structured sample covering statements that address four big subissues (the key elements in social cognition models (35)) explaining potential deviations from rational consideration of medium distance travel costs and benefits: (1) motivation for travel or mode choice, (2) stability of travel preferences, (3) control over alternatives, and (4) repetition of journeys. The advantage of using a structured sample, is that structured samples are composed systematically and thus avoid the risk that some issue components are over- or under-sampled, introducing some kind of bias into the Q-sample (32).

TABLE 1 Structured Q-Sample (Statements Numbered Randomly)

\begin{tabular}{|c|c|c|}
\hline CATEGORY & NR & STATEMENTS \\
\hline \multicolumn{3}{|l|}{ 1. Motivation } \\
\hline \multicolumn{3}{|c|}{ 1a. Instrumental/reasoned } \\
\hline \multirow{2}{*}{ Costs } & 13 & For me, traveling by public transport is more expensive than traveling by car. \\
\hline & & Travel costs play an important role in my mode choice. \\
\hline Travel time/speed & 40 & Door to door travel time plays an important role in my mode choice. \\
\hline Reliability & 18 & I find the reliability of travel time important. \\
\hline Comfort & & $\begin{array}{l}\text { To me, things like comfort, privacy and safety are more important than travel costs } \\
\text { and travel time }\end{array}$ \\
\hline $\begin{array}{l}\text { Environment } \\
\text { friendly }\end{array}$ & 4 & $\begin{array}{l}\text { I am not really price- or time-sensitive, environmental aspects are most important to } \\
\text { me. }\end{array}$ \\
\hline \multirow{2}{*}{$\begin{array}{l}\text { Protection: } \\
\text { social safety }\end{array}$} & 21 & I often feel unsafe when using public transport and at stations, especially at night. \\
\hline & 39 & Public transport is much too dirty and unsafe to be an alternative for the car. \\
\hline $\begin{array}{l}\text { Autonomy: } \\
\text { availability }\end{array}$ & & $\begin{array}{l}\text { I know very well where in my neighborhood I have access to public transport } \\
\text { services to arrive at the rail station and I have a fairly good notion of the timetable. }\end{array}$ \\
\hline \multirow{3}{*}{$\begin{array}{l}\text { Autonomy: } \\
\text { flexibility, } \\
\text { independence }\end{array}$} & & $\begin{array}{l}\text { For an active social life I need a car. Without a car I would visit my family and } \\
\text { friends less often and would make fewer leisure trips. }\end{array}$ \\
\hline & 22 & A car is not a necessity, but it does make life a whole lot easier. \\
\hline & & $\begin{array}{l}\text { On a day when I do not have my car at my disposal for a day, I am greatly } \\
\text { inconvenienced. }\end{array}$ \\
\hline $\begin{array}{l}\text { Productivity } \\
\text { en route }\end{array}$ & & $\begin{array}{l}\text { A bid advantage of traveling by train is that you can do something useful en route: } \\
\text { do some reading or take a nap. }\end{array}$ \\
\hline \multirow{2}{*}{$\begin{array}{l}\text { Overall } \\
\text { assessment }\end{array}$} & & $\begin{array}{l}\text { Before every trip, I draw a comparison between car and public transport regarding } \\
\text { travel costs, time and so forth, and select the best alternative. }\end{array}$ \\
\hline & 7 & All things considered, to me the car is superior to public transport. \\
\hline
\end{tabular}




\begin{tabular}{|c|c|c|}
\hline \multicolumn{3}{|c|}{ 1b. Symbolic/affective } \\
\hline Freedom & 36 & Only the car takes me where I want, when I want it. \\
\hline Prestige, social & 26 & You are what you drive. \\
\hline Privacy & 31 & $\begin{array}{l}\text { In the train you sometimes meet nice people. I enjoy that. The car is much duller } \\
\text { and more lonesome. }\end{array}$ \\
\hline Self-expression & 23 & $\begin{array}{l}\text { For me the car is more than a mode of transport, it is a part of my identity, a way to } \\
\text { distinguish myself from others. }\end{array}$ \\
\hline Social contacts & 32 & $\begin{array}{l}\text { A lovely view, a pleasant encounter, a surprising book, a brain wave. A train } \\
\text { journey often is an experience. }\end{array}$ \\
\hline \multicolumn{3}{|l|}{ 1c. Norms } \\
\hline \multirow[t]{2}{*}{ Personal } & 35 & $\begin{array}{l}\text { I am a dedicated follower of the four-wheel credo. The car can maybe do without } \\
\text { me for a day, but I can not do without my car. }\end{array}$ \\
\hline & 6 & Public transport is for people who can not afford a car. \\
\hline \multirow{3}{*}{ Social } & 28 & $\begin{array}{l}\text { A better environment starts with yourself. Therefore, everyone should use public } \\
\text { transport more often. }\end{array}$ \\
\hline & 41 & $\begin{array}{l}\text { Belgium is a car country. We could just as well pave all railroads and transform all } \\
\text { stations into parking garages. }\end{array}$ \\
\hline & 38 & My family and friends appreciate it when I travel by public transport. \\
\hline \multicolumn{3}{|l|}{ 2. Stability } \\
\hline \multirow{2}{*}{ Process } & 3 & $\begin{array}{l}\text { What really matters is reaching my destination and getting back, the mode of travel } \\
\text { does not matter much. }\end{array}$ \\
\hline & 29 & $\begin{array}{l}\text { Driving a car is a great pleasure. The sound of the engine, accelerating sportily at } \\
\text { traffic lights, cruising on the highway, listening to music. }\end{array}$ \\
\hline \multirow{2}{*}{$\begin{array}{l}\text { Role/context } \\
\text { dependent }\end{array}$} & 1 & For private use I do not need a car. \\
\hline & 12 & For my work I need a representative mode of transport. \\
\hline \multirow{2}{*}{ Emotion } & 5 & $\begin{array}{l}\text { I would rather look out of the compartment window at the passing landscape than at } \\
\text { the bumper of the car before me. }\end{array}$ \\
\hline & 24 & $\begin{array}{l}\text { I recall the day I got my first car very well, I had been looking forward to that day } \\
\text { for quite a while. }\end{array}$ \\
\hline \multicolumn{3}{|l|}{ 3. Control } \\
\hline \multirow[t]{2}{*}{ Control } & 19 & $\begin{array}{l}\text { I find it pleasant to plan my trips in advance and to have everything well organized } \\
\text { before I leave. }\end{array}$ \\
\hline & 15 & It is important to me to have control over my journey. \\
\hline Incomplete: costs & 17 & I am well aware of the costs of a trip, by car as well as by public transport. \\
\hline Incomplete: route & 11 & $\begin{array}{l}\text { I would rather not drive in big cities... lots of traffic, lots of traffic lights, problems } \\
\text { with parking. }\end{array}$ \\
\hline $\begin{array}{l}\text { Incomplete: } \\
\text { schedule }\end{array}$ & 2 & $\begin{array}{l}\text { As a result of all those different timetables and lines, traveling by public transport is } \\
\text { too complicated. }\end{array}$ \\
\hline Incidents & 9 & The last time I traveled by public transport was a complete disaster. \\
\hline \multicolumn{3}{|l|}{ 4. Repetition } \\
\hline $\begin{array}{l}\text { Familiarity, } \\
\text { experience }\end{array}$ & 8 & I know the public transport system pretty well because I make use of it frequently. \\
\hline Choice set & 33 & $\begin{array}{l}\text { As far as I am concerned, car and public transport both are good transport } \\
\text { alternatives. }\end{array}$ \\
\hline Habit & 37 & I always travel in the same way and find it satisfactory. \\
\hline Interdependency & 27 & Once you own a car, you'll use it for all your travel. \\
\hline Routine & 16 & $\begin{array}{l}\text { For the greater part my travel behavior is routine, I do not really give it much } \\
\text { thought. }\end{array}$ \\
\hline
\end{tabular}

\subsection{P-Set}

A Q-methodological study does not require a large number of participants (P-set) in order to find meaningful, discernible groups (28). Barry and Proops (29) illustrate that a larger P-set 
would not be of benefit in a Q study as Q operates on the assumption of 'finite diversity': Qmethodology allows the researcher to investigate the similarity and diversity of patterns across individuals without this resulting in chaotic multiplication as there are only a limited number of ordered patters within a particular discourse domain. Q-methodology uses this assumption to reveal those patterns (factors) in a structured and interpretable way. Nonetheless, Q-methodological studies have often unjustly been criticized for their reliability and hence the possibility for generalization. The most important type of reliability is replication, the fact whether the same condition of instruction leads to discourses that are schematically reliable across similarly structured yet different Q-samples, and when administered to a different set of persons. This type of reliability is assured by the fact that our Q-sample is well-structured, and by the finding that only a limited number of distinct viewpoints exist on any topic (32). The common notion of statistical reliability, regarding the ability to generalize sample results to the general population is of less concern here, as the primary purpose of Q-methodology is to identify a typology, not to test the typology's proportional distribution within the larger population (28).

Since the focus of this research lies on the modal choice between public transport and car use, participants had to be at least 18 years, the age-level for legally obtaining a driving license in Belgium. Next to age, also car possession and gender were used to balance the Pset. Thus, a three-dimensional structure of the P-set was obtained, consisting of 18 ( $3 \times 3 \times 2)$ logical combinations: three car ownership/driving license categories (car and driving license, no car and driving license, and no car and no driving license), three age categories (18-25, 2657 and $\geq 58$ ), and gender. For each of the 18 combinations two persons were searched. For the categories older males without driving license, and older males without car access, no participants were recruited, resulting in a study population of 32 persons.

\subsection{Q-Sorting}

Q-sorting is a process for which a subject models his or her point of view by rank-ordering the Q-sample statements (32). For reasons of simplicity and pragmatism, participants are not required to carry out a complete rank ordering of the Q-set items. Instead, they assign each statement to a ranking position in a fixed quasi-normal distribution, and along a simple, facevalid dimension, for example most agree to most disagree. Each person can use his or her own subjective criteria to evaluate the statements (30).

The 42 statements in this study were all printed on random numbered cards. Respondents were asked to attentively read trough all of the statements and were asked to what extent they agreed with the statements. First, they had to order them into three piles: general agree, disagree, and neutral/undecided. Next, they were asked to rank-order the statements further according the following distribution illustrated by Table 2. After sorting, participants were asked to clarify why they most agreed and most disagreed on the statements they placed under “-4 (most disagree)” and “+4 (most agree)”.

TABLE 2 Quasi-Normal Distribution

\begin{tabular}{|l|c|c|c|c|c|c|c|c|c|}
\hline Values & -4 & -3 & -2 & -1 & 0 & +1 & +2 & +3 & +4 \\
\hline Number of statements & 2 & 3 & 5 & 7 & 8 & 7 & 5 & 3 & 2 \\
\hline
\end{tabular}

Table 2 demonstrates that the distribution dictates the number of items that can be assigned to each ranking position. Thus the Q-sorting process requires each participant to assign an exact 
number of elements to each potential value. In this study, 2 elements were required at each of the extremes ( -4 and 5 ), while 8 were required at the neutral point of 0 . This restriction may alarm some researchers, yet such concerns are largely misplaced. It is in fact, quite possible to employ different forms of distribution in the context of Q-methodology. Moreover, an array of statistical comparisons demonstrated that distribution effects were virtually inexistent. Thus, the chosen distribution actually makes no noticeable contribution to the discourses which emerge from the analysis (30).

\subsection{Analysis}

To analyze the Q-sorts, and extract the underlying discourses, the PQMethod software package was used. This freeware program is an efficient software package specifically designed for Q-methodology (36). After entering all the Q-sorts in the program, the package correlates each Q-sort with every other Q-sort. This intercorrelation matrix is then factoranalyzed by the centroid procedure (29). Note that the psychometrics of Q-methodology call for the correlation and factoring of persons, as opposed to tests, traits, etc. (32). A selection of the resultant factors is then rotated using varimax rotation. Varimax rotation is consonant with one of the typical aims in using Q-methodology, namely to reveal the range of discourses in the participant group. Given this aim, it makes theoretical sense to pursue a rotated solution which maximizes the amount of variance explained by the extruded factors, and as the varimax procedure seeks this solution, it makes sense to rotate the selected factors using this procedure (30).

Different criteria were used to determine the number of factors that have to be rotated. A first criterion is that only factors with eigenvalues in excess of one should be considered for extraction (28). Eigenvalues are a measure of the relative contribution of a factor to the explanation of the total variance in the correlation matrix. Factors with an eigenvalue greater than one explain more variance than a single variable (in this case Q-sort) would (32). Eight factors met this first criterion. A second criterion is that an interpretable Q-methodological factor must have at least two Q-sorts (the ranked statements of two persons) that load significantly upon it alone (30). Sensitivity analysis showed that with five factors, one factor is only loaded by a single Q-sort. But then again, when four factors were extracted, the second criterion was met. Note that a four-factor solution was also retrieved by Kaufmann (16), Rajé (28), van Axel et al. (34) and Barry and Proops (29) suggesting that four discourses preponderate the paradigm of environmentally sustainable transport.

\section{RESULTS}

Four operant discourses to medium-distance travel decisions were found: travelers who use public transport as a dominant alternative (discourse A), car-dependent travelers (discourse B), travelers with a positive perception of using public transport (discourse C), and travelers with a preference for car use (discourse D). Five respondents did not uniquely load on one of these discourses. The four discourses account for $60 \%$ of the variation in the Q-sorts. A profile of the perspective of each discourse can be derived using the factor Q-sort values and the distinguishing characteristics of each factor. The Q-sort values are displayed in Figure 2, the distinguishing characteristics and consensus items in Table 3. For the statements themselves the reader is referred to Table 2. 

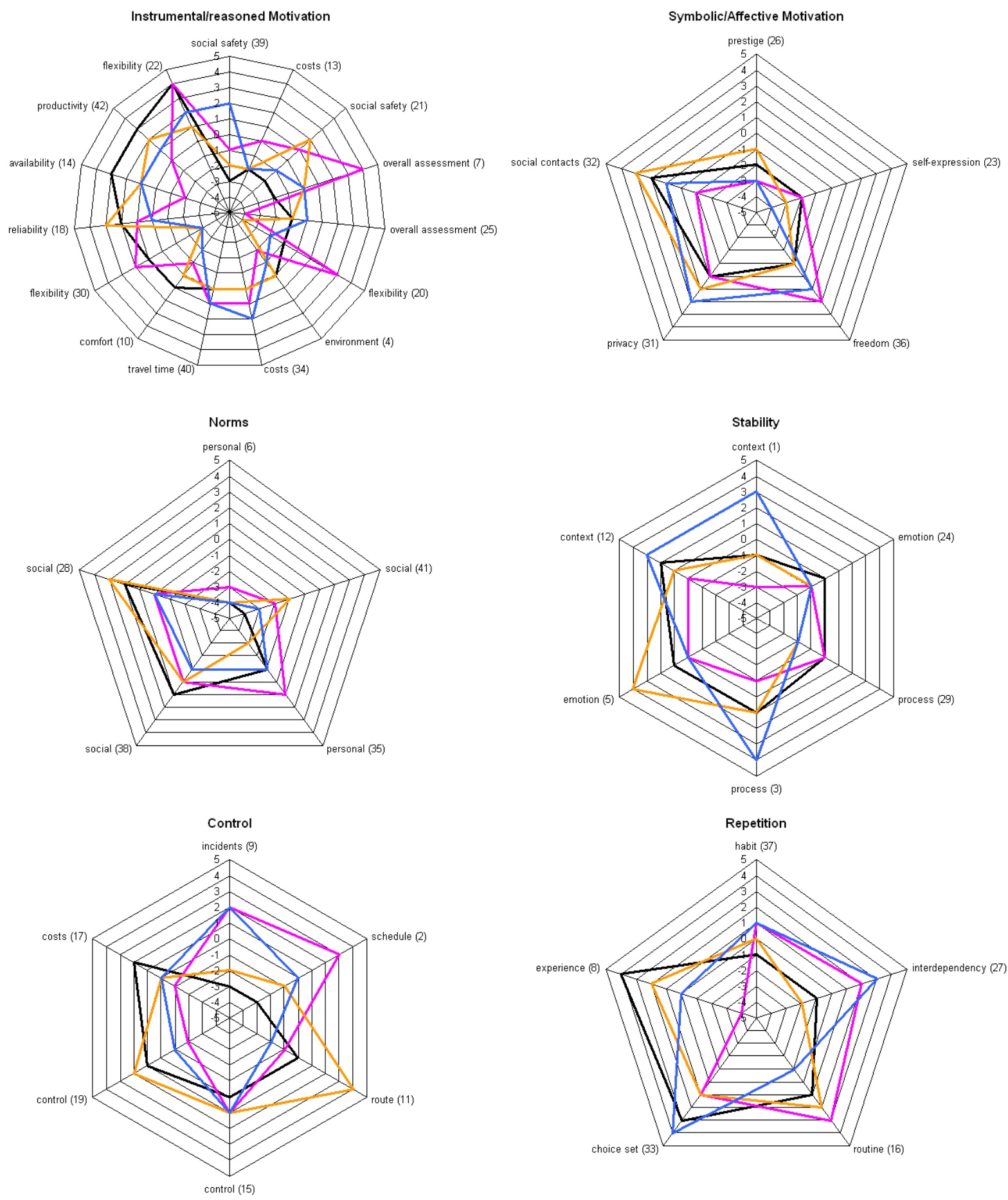

\section{FIGURE 2 Factor Q-sort values.}

The factor Q-values for each statement indicate how each group ranked the items (37). The distinguishing characteristics are contention statements that subgroup (factor) members have ranked significantly differently from other subgroups (higher or lower than overall average). Conversely the consensus statements are the items that do not distinguish between discourses 
(factors). Note that significances are calculated based on normalized factor scores (Z-scores) for each subgroup. These Z-scores denote how far each item is from the overall group mean (measured in standard deviations). A summary profile for each of the discourses is obtained by combining the information from the Q-sort values and the distinguishing characteristics (37).

TABLE 3 Distinguishing and Consensus Statements (p-value $<0.05$ )

\begin{tabular}{|c|c|c|c|c|c|}
\hline \multirow{2}{*}{ Statement category } & \multicolumn{4}{|c|}{ Distinguishing statements (statement numbers) } & \multirow{2}{*}{$\begin{array}{l}\text { Consensus } \\
\text { statements } \\
\text { (statement } \\
\text { numbers) }\end{array}$} \\
\hline & $\begin{array}{c}\text { Discourse } \\
\text { A }\end{array}$ & $\begin{array}{c}\text { Discourse } \\
\text { B }\end{array}$ & $\begin{array}{c}\text { Discourse } \\
\text { C }\end{array}$ & $\begin{array}{c}\text { Discourse } \\
\text { D }\end{array}$ & \\
\hline $\begin{array}{l}\text { Motivation } \\
\text { (instrumental/reasoned) }\end{array}$ & $7,14,42$ & $7,13,14,20,25,39$ & 20 & 39 & 4, 40 \\
\hline Motivation (symbolic/affective) & 36 & 32 & 36 & 23,26 & 31 \\
\hline Motivation (norms) & 28,38 & --- & 28,35 & --- & 6 \\
\hline Stability & --- & 1,3 & 5 & 1,3 & --- \\
\hline Control & $2,9,17,19$ & 2 & $9,11,19$ & --- & 11,15 \\
\hline Repetition & 8,27 & 8,16 & 8,27 & 8,16 & --- \\
\hline
\end{tabular}

From Table 3, it is clear that the four big sub-issues (motivation, stability, control and repletion) indeed matter in explaining potential deviations from rational consideration of medium-distance travel costs and benefits. All four categories of statements contribute significantly in explaining differences in the underlying reasons for the modal appraisal between car use and public transport, albeit car-dependent travelers differ from other travelers mainly because of instrumental/reasoned motivations. In the remainder of this section the four different discourses are further examined. Personal comments of the respondents concerning their most extreme rankings are displayed in italic and references to the statements and their corresponding factor Q-sort values are displayed in square brackets, the first number being the statement number, the latter the factor Q-sort value.

\subsection{Discourse A: Travelers Who Use Public Transport as a Dominant Alternative}

The first discourse, which is defined by 13 respondents, can be labeled as 'Travelers who use public transport as dominant alternative'. For people sharing the viewpoints of this discourse, public transport and car use are both acceptable transport alternatives $[33,+3]$, each transport alternative having its own advantages. A main advantage of traveling by public transport for this group of people, is that it allows them to do something useful while traveling [42,+3]: 'One of the main reasons why I use public transport is the fact that I can read a newspaper or a book, which otherwise I would not read due to a lack of time'. On the other hand car use is very tempting for them, because it does make their life a whole lot easier [22,+4]: 'With the car I can get anywhere, also in bad weather, the car is more convenient; I get in and I'm on track'. Either way, public transport is certainly not regarded as an inferior alternative [41,-4], $[9,-3]$ : it is not too complicated [2,-3], and not too dirty or unsafe to be an alternative for the car $[39,-3]$. Moreover, they are very familiar with the public transport system, as they make use of it frequently $[8,+4]$.

Public transport will be preferred to car use in most of the occasions [7,-2]: 'I use public transport as often as possible, nevertheless in some case I use the car'. Although travel costs are not playing an important role in their modal choice [34,0], people sharing this 
discourse are most probably stimulated to use public transport, because public transport is the least expensive alternative in most circumstances [13,-2]. Striking, is that this discourse is represented by almost all categories: people from all age categories, all driving license/car ownership groups and both sexes are represented in this group.

\subsection{Discourse B: Car-Dependent Travelers}

The second discourse, which is only defined by two female respondents, can be labeled as 'Car-Dependent Travelers'. The travelers in this discourse unilaterally prefer the car. For them, car use is a clearly superior transport option [7,+4]: 'I never use public transport'. They perceive car use as an absolute necessity to make their life more convenient $[20,+3],[22,+4]$. The latter is revealed in their travel behavior as they almost always use the car as their main travel mode [27,+2], [1;-3].

As the respondents in this group seldom use public transport, they also have limited knowledge about the public transport system [8,-4], [14,-2]: 'I do not know the public transport system, because I never use public transport.' Possible reasons are bad experiences with public transport in the past $[9,+2]$ and the fact that public transport is too complicated $[2,+3]$. Notwithstanding, people in this discourse do not denounce public transport as a system. They are convinced that public transport is needed in the society [41,-2]. In addition, they do not perceive the car as status symbol [26,-3], nor disdain people using public transport [6,-3].

\subsection{Discourse C: Travelers with a Positive Perception of Using Public Transport}

The third category of people can be typified as 'Traveler with a positive perception of using public transport'. The nine respondents sharing the viewpoints of this discourse prefer traveling by public transport because it allows them to travel in a relax environment $[5,+4]$, while usefully spending their time [32,+3], [42;+2]: 'In the train I feel at ease, while in the car I feel jaded by all the traffic jams'. Furthermore, they feel they contribute to the environment by using public transport $[28,+3]$, and avoid inconveniences experienced in city traffic [11,+4]: 'In big cities there is too much commotion in the streets, to many stressed situations, and difficulties of finding a parking spot. I rather go by foot, by bike and/or public transport then'.

Next to the emotional preference for car, the actual mode choice is also based on other motives. First, the reliability of travel times is of importance $[18,+3]$. Besides, the social security on public transport conveyances and in stations matters $[21,+2]$. All things considered, people sharing this discourse have no inherent preference for car use or public transport $[7,0]$. On the one hand, they are well aware of the available public transport options $[8,+2]$, but on the other hand, car use can facilitate the fulfillment of people's travel needs. Nevertheless, this people are not car-dependent $[20,-4]$, [30,-3], nor consider the car as a status symbol [6,-4], [23,-3].

\subsection{Discourse D: Travelers with a Preference for Car Use}

The last group of people that can be distinguished can be denominated as 'Travelers with a preference for car use'. The three persons defining this group base their modal choice on the 
accessibility of their destination $[3,+4]$, as well as on the travel costs $[34,+2]$. Car use offers them several advantages, while public transport coincides with some barriers. For them, the car is considered as a convenient transport mode that when once possessed, is used as frequently as possible $[22,+2]$, $[27,+3]$. Public transport, on the other hand, is considered to be an unsafe transport mode [39,+2], with which the people in this group had bad experiences in the past $[9,+2]:$ 'I had several bad connections in the past'.

Despite the arguments favoring car use, people sharing the viewpoints of this discourse value public transport and car use as equal alternatives $[33,+4]$. This can be explained by the fact that car use is not regarded as a status symbol, it is not a transport mode for people who cannot afford to buy a car $[6,-4]$, and that the car is not a part of a persons identity [23,-4], [26,-3]: 'It is ridiculous to distinguish oneself from others by a car'.

\subsection{Similarities and Differences between the Discourses}

From the elaboration on the four discourses important differences between the discourses could be highlighted. Most prevalent differences include the knowledge of [8] and experience with [9] available transport options, the perceived difficulty to use them [2] and the corresponding general assessment of public transport [7]. In spite of the differences also similarities can be derived: on certain aspects concerning modal choice, the respondents of different discourses share similar views. An important finding is that none of the four discourses considers the car as a status symbol (statements 6, 23, 26 and 41), evidencing that public transport is a generally accepted transport mode in Flanders. Moreover the door to door travel time plays no significant role in the choice of transport mode, travel time reliability is of much higher importance.

\section{DISCUSSION}

The Q-study carried out, pointed out that four groups of people can be distinguished. This finding is consonant with the finding of Kaufman (16) who used cluster analysis and factor analysis to discriminate between different groups of travelers. When the four discourses retrieved in the Q-study are compared to the groups of travelers Kaufman distinguishes, some correspondences are found, especially for the group that Kaufman labels as the 'exclusive motorists'. These are individuals who never use public transportation, even though they have a high quality service in close proximity to their home. They are marked by a tendency to choose their destinations according to the perceived ease with which they can use their cars. This group corresponds strongly to the 'car-dependent travelers'. Both groups have a unilateral preference for car use. These travelers are the most difficult to convince to change their travel behavior.

The other groups Kaufman discusses are 'civic ecologists', travelers whose use of public transport stems more from a value system which the person wants to adhere than with the quality of the transport offer; 'motorists constrained into using public transport', individuals that use the car each time that traffic and parking conditions permit it, and will not revert to public transport, except, when the opposite is true; and 'open to all possibilities' individuals whose modal practices result from an efficiency assessment of all possible modes of transport. Underlying motivations of these groups overlap with the three remaining discourses retrieved by the Q-study reported in this paper, but unique one-to-one matches 
were not retrieved. Nonetheless both studies highlight important underlying rational and subjective motives of travel behavior relevant for policy makers.

\section{CONCLUSION AND POLICY ADVICE}

The Q-methodological study that was carried out provided insights that are important to understand, and eventually change travel behavior of individuals. It was found that four discourses preponderate the paradigm of environmentally sustainable transport. The four groups of people differed in attitude towards public transport. One group differed significantly from the others, namely the car-dependent travelers. For individuals in this group, travel behavior is pure routine. Attempts to shift these individuals' mode choice towards environment-friendly transport modes such as public transport will face a high resistance as these people are highly dependent on their car use. The other groups differ less harshly from one another. A common feature for these three groups is that they do not inherently prefer one transport mode over the other, albeit slight preferences for a specific transport mode exist. Each group has its own underlying reasons to choose a particular transport alternative. Differences in these reasons are important for policy makers, as they can aid in removing barriers to use public transport. Recall that the primary purpose of Qmethodology is to identify a typology, not to test the typology's proportional distribution within the larger population. Therefore, other studies employing different underling techniques are required to further generalize the results.

When the rational, economic motives are discussed, individuals evaluate travel time reliability as most important, the door-to-door travel time itself is of minor importance. Thus, the challenge for policy makers is to make the travel times more reliable and predictable. Separate bus lanes and traffic light manipulation are two hard pull measures that can aid in limiting the number of bottle necks, and thus increasing the reliability. Moreover, policy makers have to search for the delicate balance between the number of stops (maximum number of passengers) and travel time reliability: the more stops, the lower the travel time reliability. This problem can be partially solved by introducing more mutual exclusive bus lines (separate bus lines service, other bus stops) and a higher frequency of busses.

Next to travel time reliability, also travel costs play a role. Most people are convinced that costs are lower for public transport than for car, indicating that low bus fares are important to stimulate people to use public transport. Public transport can be made even more relative attractive, when hard push measures such as making the costs of travelling more variable by road or congestion charging are taken.

When the subjective motives are discussed, the differences between the different groups of travelers were more pronounced. These differences provide a solid social basis to further shift the modal split towards public transport. Imaging traveling by public transport as spending useful time is a possible way forward. Soft pulling measures such as advertising campaigns can illustrate that the time spent on public transport can be spent usefully by working or reading. Electric points and internet plug-ins and wireless internet on trains can further stimulate this image. Next to increasing the benefits of using public transport, policy makers should also pay attention to removing psycho-social barriers. The neighborhood of public transport stations can be revaluated using new urban plans, which will increase the social control and gives travelers a safer feeling. In addition this safety feeling can be further improved by higher presence of policemen. Finally, the ease of using public transport can be 
improved by providing personal information such as person-based travel planners and more simple travel guides, where redundant information is left out.

\section{ACKNOWLEDGEMENTS}

The authors would like to thank Katrien Declercq, Els Hannes and Kris Brijs for their contribution to this paper.

\section{REFERENCES}

(1) Haustein, S., and M. Hunecke. Reduced use of environmentally friendly modes of transportation caused by perceived mobility necessities: an extension of the theory of planned behavior. Journal of Applied Social Psychology, Vol. 37, No. 8, 2007, pp. 1856-1883.

(2) Steg, L. Can public transport compete with the private car. IATSS Research, Vol. 27, No. 2, 2003, pp. 27-35.

(3) Gärling, T., and G. Schuitema. Travel demand management targeting reduced private car use: effectiveness, public acceptability and political feasibility. Journal of Social Issues, Vol. 63, No. 1, 2007, pp. 139-153.

(4) Tertoolen, G., D. van Kreveld, and B. Verstraten. Psychological resistance against attempts to reduce private car use. Transportation Research Part A: Policy and Practice, Vol. 32, No. 3, 1998, 171-181.

(5) Kingham S., J. Dickinson, and S. Copsey. Travelling to work: will people move out of their cars. Transport Policy, Vol. 8, No. 2, 2001, pp. 151-160.

(6) Bamberg S. Is a stage model a useful approach to explain car drivers' willingness to use public transportation. Journal of Applied Social Psychology, Vol. 37, No. 8, 2007, pp. 1757-1783.

(7) Ministerie van de Vlaamse Gemeenschap. Mobility plan Flanders (In Dutch: Ontwerp Mobiliteitsplan Vlaanderen). Departement Leefmilieu en Infrastructuur, Mobiliteitscel, 2001.

(8) Kennisscentrum Statistiek. Mobility figures (In Dutch: Mobiteitscijfers). http://aps.vlaanderen.be/statistiek/cijfers/stat_cijfers_mobiliteit.htm. Accessed May 7, 2008.

(9) Kuppam, A.R., R.M. Pendyala, and S. Rahman. Analysis of the role of traveler attitudes and perceptions in explaining mode-choice behavior. In Transportation Research Record: Journal of the Transportation Research Board, No. 1676, Transportation Research Board of the National Academies, Washington, D.C., 1999, pp. 68-76. 
(10) Johansson, M.V., T. Heldt, and P. Johansson. The effects of attitudes and personality traits on mode choice. Transportation Research Part A: Policy and Practice, Vol. 40, No. 6, 2006, pp. 507-525.

(11) Steg, L., C. Vlek, and G. Slotegraaf. Instrumental-reasoned and symbolic-affective motives for using a motor car. Transportation Research Part F: Traffic Psychology and Behaviour, Vol. 4, No. 3, 2001, pp. 151-169.

(12) Heath, Y., and R. Gifford. Extending the theory of planned behavior: predicting the use of public transportation. Journal of Applied Social Psychology, Vol. 32, No. 10, 2002, pp. 2154-2189.

(13) Nilsson, M. and R. Küller. Travel behaviour and environmental concern. Transportation Research Part D: Transport and Environment, Vol. 5, No. 3, 2000, pp. 211-234.

(14) Nordlund, A.M., and J. Garvill. Effects of values, problem awareness, and personal norm on willingness to reduce personal car use. Journal of Environmental Psychology, Vol. 23, No. 4, 2003, pp. 339-347.

(15) Bamberg, S., M. Hunecke, M., and A. Blöbaum. Social context, personal norms and the use of public transportation: two field studies. Journal of Environmental Psychology, Vol. 27, No. 3., 2007, pp. 190-203.

(16) Kaufmann, V. Modal practices: from the rationales behind car and public transport use to coherent transport policies: case studies in France \& Switzerland. World Transport Policy and Practice, Vol. 6, No. 3, 2000, pp. 8-17.

(17) Anable, J., and B. Gatersleben. All work and no play? The role of instrumental and affective factors in work and leisure journeys by different travel modes. Transportation Research Part A: Policy and Practice, Vol. 39, No. 2-3, 2005, pp. 163-181.

(18) Ellaway, A., S. Macintyre, R. Hiscock, and A. Kearns. In the driving seat: psychosocial benefits from private motor vehicle transport compared to public transport. Transportation Research Part F: Traffic Psychology and Behaviour, Vol. 6, No. 3, 2003, pp. 217-231.

(19) Hiscock, R., S. Macintyre, A. Kearns, and A. Ellaway. Means of transport and ontological security: Do cars provide psycho-social benefits to their users. Transportation Research Part D: Transport and Environment, Vol. 7, No. 2, 2002, pp. 119-135.

(20) Huey, J.A., and P.B. Everett. Immediate benefits: the reason for the car's success and transit's failure. In Transportation Research Record: Journal of the Transportation Research Board, No. 1521, Transportation Research Board of the National Academies, Washington, D.C., 1996, pp. 65-70. 
(21) OECD. Communicating environmentally sustainable transport: the role of soft measures. OECD (Organisation for economic cooperation and development, Paris, France, 2004.

(22) Guiver, J.W. Modal talk: discourse analysis of how people talk about bus and car travel. Transportation Research Part A: Policy and Practice, Vol. 41, No. 3, 2007, pp. 233248.

(23) Eriksson, L., J. Garvill, and A.M. Nordlund. Acceptability of single and combined transport policy measures: the importance of environmental and policy specific beliefs. Forthcoming in Transportation Research Part A: Policy and Practice, 2008.

(24) Marshall, S., and D. Banister. Travel reduction strategies: intentions and outcomes. Transportation Research Part A: Policy and Practice, Vol. 34, No. 5, 2000, pp. 321338.

(25) Hensher, D.A. Climate change, enhanced greenhouse gas emissions and passenger transport: what can we do to make a difference. Transportation Research Part D: Transport and Environment, Vol. 13, No.2, 2008, pp. 95-111.

(26) Anable, J. 'Complacent car addicts' or 'aspiring environmentalists? Indentifying travel behaviour segments using attitude theory. Transport Policy, Vol. 12, No. 1, 2005, pp. 65-78.

(27) Bamberg, S., D. Rölle, and C. Weber. Does habitual car use not lead to more resistance to change of travel mode. Transportation, Vol. 30, No. 1, 2003, pp. 97-108.

(28) Rajé, F. Using Q methodology to develop more perceptive insights on transport and social inclusion. Transport Policy, Vol. 14, No. 6, 2007, pp. 467-477.

(29) Barry, J., and J. Proops. Seeking sustainability discourses with Q methodology. Ecological Economics, Vol. 28, No. 3, 1999, pp. 337-345.

(30) Watts, S., and P. Stenner. Doing Q methodology: theory, method and interpretation. Qualitative Research in Psychology, Vol. 2, No.1, 2005, pp. 67-91.

(31) Brown, S.R. A primer on Q methodology. Operant Subjectivity, Vol. 16, No. 3/4, 2004, pp. 91-138.

(32) McKeown, B.F., and D.B. Thomas. Q Methodology. Sage, Newbury Park, C.A., 1988.

(33) Stephenson, W. The study of behaviour: Q technique and its methodology. University of Chicago Press, Chicago, 1953. 
(34) Van Exel, N.J.A., G. de Graaf, and P. Rietveld. Getting from A to B: Operant approaches to travel decision making. Operant Subjectivity, Vol. 27, No. 4, 2005, pp. 194-216.

(35) Armitage C.J., and M. Conner. Social cognition models and health behaviour: a structured review. Psychology and Health, Vol. 15, No. 2, 2000, pp. 173-189.

(36) Schmolck, P. PQMethod 2.11, 2002. www.lrz-muenchen.de/ schmolck/qmethod/. Accessed March 23, 2008.

(37) Donner, J.C. Using q-sorts in participatory processes: an introduction in the methodology. Social Development Papers, No. 36, 2001, pp. 24-59. 